\title{
EXPERIMENTAÇÃO ANIMAL NA SOCIEDADE DE RISCO E A VIOLAÇÃO DO PRINCÍPIO DA IGUAL CONSIDERAÇÃO DE INTERESSES
}

\author{
ANIMAL TESTING IN THE RISK SOCIETY AND VIOLATION OF THE \\ PRINCIPLE OF EQUAL CONSIDERATION OF INTERESTS
}

\author{
${ }^{1}$ Rafael Speck de Souza
}

\section{RESUMO}

O presente artigo busca analisar a prática da experimentação animal sob o paradigma da Sociedade de Risco, dos Direitos Animais, e em que ponto tais pesquisas ferem o princípio da igual consideração de interesses semelhantes, preconizado por Peter Singer e outros filósofos morais. Por um lado, coloca-se em questão o fato de se pretender transpor os resultados de um experimento com animais às reações com seres humanos, e os respectivos critérios de segurança (ou insegurança) adotados pela ciência. Por outro lado, avalia-se o quanto tais modelos animais são considerados uma prática especista, que não leva em consideração os interesses de espécies não humanas sencientes (que possuem a capacidade de sofrer). Para a obtenção dos objetivos colimados utilizar-se-á o método histórico, comparativo e dedutivo. Serão utilizados como fontes de pesquisa, eminentemente bibliográfica, livros, artigos e periódicos. Adotar-se-á como referenciais teóricos a teoria social do risco proposta pelo sociólogo alemão Ulrich Beck e a teoria da ética animalista defendida pelo filósofo australiano Peter Singer.

Palavras-chave: Experimentação animal, Sociedade de risco, Direitos animais, Ética animal, Princípio da igual consideração de interesses

\footnotetext{
${ }^{1}$ Mestre em Direito, Estado e Sociedade pela Universidade Federal de Santa Catarina - UFSC, Florianopolis - SC (Brasil). E-mail: rafaelspk@gmail.com
} 


\begin{abstract}
This paper seeks to analyze the practice of animal testing under the paradigm of the Risk Society, Animal Rights, and in which point such research hurts the principle of equal consideration of like interests advocated by Peter Singer and other moral philosophers. On the one hand, this paper calls into question the attempt to transfer the results of an experiment with animals to reactions in humans, and the security criteria (or insecurity) adopted by science. On the other hand, an evaluation is made of how much these animal models are considered speciesist practice, which does not take into account the interests of non-human sentient species (which are capable of suffering). The historical, comparative and deductive methods have been used in order to reach the intended goals. The sources of research used are mostly bibliographical: books, papers and journals. Theoretical references adopted were the risk society theory proposed by German sociologist Ulrich Beck and the animal ethics theory advocated by the Australian philosopher Peter Singer.
\end{abstract}

Keywords: Animal testing, Risk society, Animal rights, Animal ethics, Principle of equal consideration of like interests 


\section{INTRODUÇÃO}

O presente artigo pretende analisar o fenômeno da experimentação animal, a partir das lentes da teoria da Sociedade de Risco proposta pelo sociológico alemão Ulrich Beck, e da teoria dos Direitos Animais trazida pelo filósofo australiano Peter Singer, questionando-se em que ponto tais pesquisas ferem o princípio da igual consideração de interesses semelhantes. Muito se argumenta no sentido de que pesquisas com animais são imprescindíveis para o desenvolvimento da ciência e para a cura de doenças. Este artigo pretende contrapor tal argumento, procurando mostrar que os modelos animais, ao revés, representam riscos à vida de seres humanos, porquanto apoiados em um "critério de loteria", utilizando-se as palavras de Beck.

$\mathrm{O}$ artigo pretende ainda demonstrar que o uso de animais em pesquisas constitui uma prática que viola o princípio da igual consideração de interesses semelhantes, eis que alicerçado na ideia da objetificação animal, a qual desconsidera o fato de que os animais sentem dor e sofrimento quando submetidos a tais experimentos. No âmago da questão, estaria o especismo, o preconceito dos seres humanos para com as outras espécies, a reforçar a ideia de que os animais são inferiores e destituídos de um valor intrínseco (valor em si mesmo).

Destaca-se a relevância do tema, eis que o campo de utilização de animais em experiências é o que evidencia mais claramente o especismo, ao lado do uso de animais para alimentação, sendo praticado de modo sistemático e em larga escala. De modo reflexo, tal prática atinge diretamente os seres humanos, colocando em risco sua saúde.

$\mathrm{Na}$ primeira seção, abordar-se-á os fundamentos do paradigma da Sociedade de Risco, apresentando-se também breve panorama histórico (o zeitgeist) que circundava o nascimento de referida teoria.

Na segunda seção, adentrar-se-á na perspectiva quantitativa do risco, na fixação de seus níveis de tolerância, e o quanto é dificultoso estabelecer-se parâmetros de tolerabilidade ou toxidade a partir de um modelo animal.

$\mathrm{Na}$ terceira e última seção, apresentar-se-á o princípio da igual consideração de interesses semelhantes, um princípio básico de igualdade que pode servir de norte para se enfrentar tal prática especista.

Como referenciais teóricos, serão utilizadas a teoria da Sociedade de Risco de Ulrich 
Beck e a teoria dos Direitos Animais defendida por Peter Singer. Para a obtenção dos objetivos colimados utilizar-se-á o método dedutivo, histórico e comparativo. Serão utilizados como fontes de pesquisa, eminentemente bibliográfica, livros, artigos e periódicos, tanto no meio eletrônico como impresso.

\section{PARADIGMA DA SOCIEDADE DE RISCO}

A expressão sociedade de risco foi proposta pelo sociólogo alemão Ulrich Beck, em obra homônima, objetivando dar resposta à atual crise ecológica que põe em risco, nada menos do que a sobrevivência da espécie humana.

Beck (2011, p. 7) lança um novo olhar para o entendimento da real dimensão de catástrofes históricas ocorridas no Século XX (entre elas: as duas guerras mundiais, Auschwitz, Harrisburg, Hiroxima e Nagasaki, Bhopal e, por último, Chernobyl).

Objetivando mostrar o zeitgeist, o ideário que ensejou a elaboração da obra, parte dos eventos acima mencionados será aqui brevemente descrita. Em segundo momento, adentrar-se à teoria do risco preconizada por Beck.

Ao término da Segunda Guerra Mundial (1939-1945), os americanos já haviam conquistado Okinawa e Iwoshima, e, a qualquer momento, esperava-se a invasão de Tóquio. Mas o presidente dos Estados Unidos da América, Harry Truman, mostrava-se impaciente. Querendo de imediato a rendição incondicional dos japoneses (e talvez pretendendo mostrar ao mundo o incrível poder bélico dos EUA), ele manda jogar sobre Hiroxima uma arma desconhecida e impressionante - a bomba atômica. Em 6 de agosto de 1945, a primeira bomba atômica é atirada sobre seres humanos. Em 9 de agosto de 1945, outra bomba é jogada sobre Nagasaki (ANTUNES, 1977, p. 27).

Face à precisão de detalhes, faz-se imperiosa a transcrição a seguir, ocorrida há exatos 70 anos:

\footnotetext{
A surpresa do fato atinge a todos, mesmo os vencedores. O homem, pela primeira vez na história, mostrava possuir o poder até então somente atribuído aos deuses. As cenas de Hiroxima e Nagasaki destruídas correm o mundo. Calcula-se que em Hiroxima havia uma população de 480.000 pessoas das quais cerca de 240.000 foram mortas imediatamente. Em Nagasaki, na época, viviam 260.000 indivíduos, dos quais 40.000 morreram. A partir dessa época os efeitos da radiação atômica fizeram muitas outras vítimas. Nos últimos trinta anos os dados oficiais apontam cerca de 200.000 mortes para Hiroxima e 170.000 para Nagasaki. Além das cifras, ficaram para sempre os relatos de cenas impressionantes: corpos mutilados voavam sob os céus das duas cidades queimadas; alguns viam suas peles abrirem-se, como seccionadas
} 
por um bisturi de fogo, outros, mais felizes, eram destruídos antes que chegassem a entender o que estava ocorrendo. O espetáculo posterior à queda das bombas desafia o fantástico.

Impressões colhidas de sobreviventes revelam que todos tinham a sensação de que a bomba explodira exatamente sobre suas cabeças. [...]. Muito maior, porém, que a dor física e o desespero da destruição total de duas cidades, foi a destruição da consciência humana de quem sobreviveu a Hiroxima e Nagasaki. [...]. Eles [os sobreviventes] trazem a lembrança de tudo quanto se pretende esquecer: a confiança no futuro da humanidade construída cuidadosamente durante séculos e dissolvida por um único piloto, por uma única bomba, em alguns minutos. [...]. Hiroxima e Nagasaki não podem ser esquecidas. As armas atômicas não criaram apenas essas vítimas, que com o tempo desaparecerão, mas sim o caos para os valores humanos. $\mathrm{E}$, no entanto, as bombas que destruíram as duas cidades japonesas são atualmente brinquedos infantis no arsenal tático contemporâneo (ANTUNES, 1977, p. 28).

Em 4 de dezembro de 1984, em Bhopal, capital de Madhia Pradesh, na Índia, o vazamento de um gás altamente venenoso (isocianato de metila, proveniente de uma fábrica de agrotóxicos) causou a morte de mais de três mil pessoas, deixou vinte mil pessoas cegas e duzentas mil feridas.

Em 26 de abril de 1986, a pequena cidade de Chernobyl, situada a oitenta quilômetros de Kiev, capital da Ucrânia, vivenciara o maior acidente nuclear da História. A explosão de um dos quatro reatores da usina de Chernobyl provocou a morte, por câncer, de nove mil pessoas, segundo os dados da Organização Mundial de Saúde. Todavia, essa estatística é contestada. Para o Greenpeace, o número correto seria 93 mil, segundo pesquisas de sessenta cientistas da Ucrânia, Belarus e Rússia.

Poucos dias após o acidente nuclear de Chernobyl, viria a público, em maio de 1986, a elaborada teoria do risco de Ulrick Beck, na sua obra precursora Sociedade de risco: rumo a uma outra modernidade. A sincronicidade entre o fatídico acidente nuclear e a publicação da obra, deu a esta projeção mundial e abrira espaço para o debate político acerca do progresso econômico a qualquer custo e os revezes da tecnologia sobre o ambiente.

Em 2006, às vésperas de completar 20 anos do acidente em Chernobyl, um estudo apontou que o desastre na Ucrânia gerou a contaminação de cerca de $40 \%$ de todo o território europeu e alertou que o número de vítimas pode chegar a 60 mil. Após o desastre nuclear de Chernobyl, uma estrutura (que recebera o nome de sarcófago) fora construída para evitar que a radiação continuasse a sair de dentro da usina, bem como para conter as aproximadas 200 toneladas de material radioativo lá guarnecidos até hoje.

Com esses exemplos, Beck procura demonstrar, como ponto de partida de seu trabalho, que os riscos decorrentes da modernização destacam-se dos riscos encontrados, por exemplo, na Idade Média e na Idade Moderna (esta, do final do século XIX à primeira metade 
do século $\mathrm{XX}$ ), por ser "produto de série do maquinário industrial do progresso, sendo sistematicamente agravados com seu desenvolvimento ulterior" (BECK, 2011, p. 26).

Tais riscos, que se manifestam no plano espacial e temporal, já se encontram diluídos, em face de seu caráter transfronteiriço e transgeracional (transcendem fronteiras e gerações).

Evocando o exemplo de Chernobyl, poder-se-ia dizer que ainda não nasceram todos os seres humanos afetados pelos efeitos da radiação nuclear (GARCIA, 2006, p. 7).

A teoria do risco de Beck possui um amplo espectro de situações, que vão desde o uso da energia nuclear até o desenvolvimento de tecnologias reprodutivas. Uma marca relevante dos novos riscos é o seu caráter global, que ultrapassam as fronteiras e as capacidades nacionais. Mas, acima de tudo, está o surgimento de situações para as quais não se podem encontrar respostas conclusivas nas ciências duras (FREITAS, 2005, p. 105).

Para Beck, os macroperigos dessa nova sociedade caracterizam-se por: a) não encontrarem limitações espaciais ou temporais; b) não se submeterem a regras de causalidade e aos sistemas de responsabilidade; e, sobretudo, c) não ser possível a sua compensação, em face do potencial de irreversibilidade de seus efeitos, que anulam as fórmulas de reparação pecuniária (MORATO LEITE; AYALA. 2004, p. 18).

Guattari (2003, p. 24) ressalta que:

\begin{abstract}
Chernobyl e a Aids nos revelaram brutalmente os limites dos poderes técnicocientíficos da humanidade e as 'marchas à ré' que a 'natureza' nos pode reservar. É evidente que uma responsabilidade e uma gestão mais coletiva se impõem para orientar as ciências e as técnicas em direção a finalidades mais humanas. Não podemos nos deixar guiar cegamente pelos tecnocratas dos aparelhos de Estado para controlar as evoluções e conjugar os riscos nesses domínios, regidos no essencial pelos princípios da economia de lucro.
\end{abstract}

Sobre a emergência do paradigma da sociedade de risco, Beck et al. (1997, p. 16) acrescentam que, a transição do período industrial para o período de risco da modernidade ocorre de forma indesejada, despercebida e compulsiva, no despertar do dinamismo autônomo da modernização, seguindo o padrão de efeitos colaterais. A sociedade de risco não é uma opção que se pode escolher ou rejeitar no decorrer de disputas políticas. Ela surge na continuidade dos processos de modernização autônoma, que são cegos e surdos a seus próprios efeitos e ameaças. De maneira cumulativa e latente, estes últimos produzem ameaças que questionam e finalmente destroem as bases da sociedade industrial. 
A sociedade contemporânea vê-se, por vezes, envolvida em meio a atividades que, por detrás de benesses sedutoras, ocultam riscos. Este clandestino, o risco, oculto na bagagem do progresso, não respeita fronteiras e nem segmentos de classes - embora inequivocamente os mais abastados consigam geralmente maiores proteções contra os riscos (MARCHESAN, 2004, p. 142-143).

Não é difícil concluir, pois, que o modelo de desenvolvimento vigente na sociedade ainda encontra-se marcado pelo reducionismo econômico e, nas palavras de Vieira (LEFF, 2006, p. 9-10), pela mercantilização progressiva (e intensiva) de todas as esferas da existência humana (tudo, ao final, é reduzido à moeda e à rentabilidade).

Canotilho (2003, p. 1354), ao fazer uma crítica à teoria da constituição, assevera que é pelos trilhos ambientais que se aloja no seio da sociedade uma injustiça essencial, sendo as instituições jurídicas - a começar logo pela constituição - incapazes de lhes dar resposta eficaz.

E prossegue o constitucionalista português:

\begin{abstract}
Expliquemos melhor. O paradigma da sociedade de risco obriga a teoria da constituição a compreender novos conceitos da teoria social como é, precisamente, o conceito de risco. Ao lado de categorias e conceitos jurídicos como contrato, direito subjectivo, indivíduo, capital, trabalho, classe, integração, racionalização, o conceito de risco parece cristalizar as experiências fundamentais das sociedades altamente industrializadas. Qualquer que seja o conceito de risco (e existem vários conceitos, ou, pelo menos, várias acentuações), ele aponta para: (1) os perigos (conhecidos e desconhecidos) gerados pela moderna tecnologia; (2) as ameaças de toda a civilização planetária (Beck); (3) as potencialidades do domínio tecnológico da natureza e da pessoa; (4) os desafios colocados às comunidades humanas no plano da segurança e previsibilidade perante eventuais catástrofes provocadas pela técnica e pela ciência (CANOTILHO, 2003, p. 1354).
\end{abstract}

Através da proteção constitucional do meio ambiente, sobretudo, frente à intitulada sociedade de risco, há que se buscar um sentido retributivo dos benefícios (em geral, monopolizados) e dos custos ambientais (sempre socializados). É o que Canotilho chama de assinalagmaticidade do risco.

Um dos problemas fundamentais da sociedade de risco é o da radical assinalagmaticidade do risco. Quer-se com isto dizer que o risco de catástrofes civilizatórias (Bophal, Chernobyl, terrorismo) é criado por uns e suportado por outros. Quem participa nas decisões de risco são organismos e organizações a quem falta legitimação democrática para decidir sobre a vida e a morte de comunidades inteiras. Por último, a localização das fontes de risco pauta-se, não raras vezes, por critérios de injustiça ambiental, situando indústrias 
e atividades perigosas nas zonas e países mais desprotegidos, geralmente periféricos, em termos econômicos, sociais, culturais, científicos (CANOTILHO, 2003, p. 1354).

Passa-se, agora, à análise do fenômeno da experimentação animal à luz da teoria da sociedade de risco.

\section{ANÁLISE TOXICOLÓGICA: PERSPECTIVA QUANTITATIVA DO RISCO}

Segundo Catarina Frade (2009, p. 56), uma das formas de se avaliar efeitos adversos do risco consubstancia-se na análise toxicológica, através de experiências com animais e subsequente formulação de modelos animais. Nessa perspectiva, busca-se apenas identificar a relação de causalidade entre um determinado agente de risco e as pessoas ou outros seres vivos afetados por ele. A sua normatividade traduz-se, assim, na proteção da saúde humana através da fixação de níveis de tolerância ao risco que limitem a exposição dos seres humanos a determinados agentes perigosos. Esta é uma concepção unidirecional do risco, qual seja, a lesão da saúde ou do ambiente - abordagem essa, deveras criticável por ignorar prejuízos de outra natureza que são também sentidos pelas pessoas (entre eles, os sociais, econômicos, culturais, éticos) $)^{1}$.

Beck (2011, p. 82-84) explica que toda definição de limites de tolerância se apoia em pelo menos 2 (duas) falácias: a) trata-se de equívoco estender os resultados de um experimento com animais às reações dos seres humanos; b) o efeito sobre o ser humano em última medida só pode ser estudado de maneira confiável com o ser humano.

Acerca do primeiro item supracitado, Beck esclarece ser um erro transpor resultados de pesquisa em animais para seres humanos, já que este está baseado em um critério de loteria, senão vejamos:

Tomemos o exemplo do veneno de Seveso, o TCCD [...]. Ele surge durante a produção de um grande número de produtos químicos, como por exemplo, conservantes de madeira, herbicidas e desinfetantes. [...]. Os efeitos cancerígenos do TCCD foram comprovados em duas espécies animais. A substância foi-lhes empurrada goela abaixo. Mas então a metódica pergunta-chave [...]: quanto disto o ser humano é capaz de suportar? Mesmo entre animais de pequeno porte, as reações foram muito variadas: porcos-da-índia, por exemplo, foram de dez a vinte vezes mais resistentes que os camundongos e de 3 mil a 5 mil vezes mais sensíveis que os hamsters (BECK, 2011, p. 82-83).

\footnotetext{
1 Em termos teóricos formais, existe uma clivagem científica na forma de se abordar os fenômenos de risco, entre as teorias que adotam uma concepção objetiva do risco e as que o encaram como uma construção social. Para as teorias objetivistas, os riscos são realidades físicas, frequentemente mensuráveis. Já para as teorias construtivistas, os riscos são arquiteturas ou artefatos sociais produzidos por indivíduos, grupos sociais ou instituições, de acordo com o contexto onde estão inseridos e os respectivos interesses e valorações (FRADE, 2009, p. 54).
} 
Restaria, pois, o questionamento de como se chegar, das extremamente inconstantes reações dos animais não humanos às reações humanas, inteiramente desconhecidas? A esta pergunta, Beck sintetiza:

Somente seguindo o modelo de loteria - marcar os números e esperar. Como na loteria, cada um tem seu "método". Na loteria dos limites de tolerância, ele é chamado de "fator de segurança". No que consiste um "fator de segurança"? No que consiste um fator de segurança é algo que a "práxis" ensina [...]. Isto é: não basta marcar os números, é preciso esperar. Mas isto é algo que já se podia saber de saída. Para isso não era necessário maltratar os animais. [...]. Os limites de tolerância certamente desempenham a função de uma descontaminação simbólica. Ao mesmo tempo, são sedativos simbólicos contra as notícias que se acumulam a respeito de contaminações. Eles sinalizam que alguém pelo menos se esforça e toma conta, Faticamente, seu efeito é fazer com que o ponto a partir do qual se fazem experimentos com seres humanos seja um pouco adiado. Mas nenhum caminho passa ao largo disto: somente quando a substância é colocada em circulação é que se pode descobrir que efeitos tem (BECK, 2011, p. 83-84).

No tocante ao segundo ponto trazido por Beck, acerca dos efeitos, sinale-se:

O efeito sobre o ser humano em última medida só pode ser estudado de maneira confiável com o ser humano. Não queremos, contudo, discutir novamente sobre questões éticas, e sim debruçarmo-nos inteiramente sobre a lógica experimental. A substância é trazida até as pessoas por todos os caminhos imagináveis: ar, água, cadeias alimentares, cadeias de bens de consumo etc. E? Onde está a falácia? Justamente: nada ocorre. O experimento que ocorre com o ser humano não ocorre. Ou mais precisamente: ele ocorre na medida em que a substância é administrada às pessoas, como aos animais, em certa dosagem. [...]. O experimento com o ser humano ocorre na verdade, mas justamente de forma invisível, sem controle científico sistemático, sem levantamento de dados, sem estatística, sem análise de correlações, sob o manto da ignorância dos afetados - e com o ônus da prova invertido, no caso de alguém acabar notando algo. [...]. Trata-se assim de um grande experimento permanente, com a participação compulsória da humanidade tomada involuntariamente como cobaia, sobre os efeitos de intoxicação que se acumulam em meio a ela, com o ônus da prova invertido e bastante dificultado, de modo que os argumentos nem precisam ser levados em conta já que existem limites de tolerância que são respeitados! Os limites de tolerância, que somente poderiam ser definidos com base nas reações das pessoas, são valorizados de modo a rechaçar temores e enfermidades das cobaias humanas afetadas! E isto tudo em nome da "racionalidade cientifica"! (BECK, 2011, p. 83-85).

Para se enfrentar a sociedade de risco e as decorrentes incertezas, a ferramenta utilizada há de ser a precaução, podendo-se trazer vários exemplos de sua possível aplicação: para fiscalizar empresas dedicadas à pesquisa e manipulação de material genético; controlar a produção, comercialização e emprego de técnicas, métodos e substâncias que comportem risco à vida e ao meio ambiente; vedar práticas que coloquem em risco a função ecológica da fauna e da flora ou que provoquem a sua extinção. O princípio da precaução não significa a prostração diante do medo, mas se materializa na busca da segurança do meio ambiente e da continuidade de vida (CENCI; KÄSSMAYER, 2009, p. 15). 
Quanto ao princípio da precaução, parte do Direito brasileiro o considera como sinônimo de princípio da prevenção. Todavia, conforme bem esclarecem Morato Leite e Ayala (2004, p. 71), o princípio da prevenção se dá em relação ao perigo concreto (um risco certo) ao passo que o princípio da precaução destina-se ao perigo abstrato ou potencial (um risco incerto).

Tratando-se de um perigo abstrato ou risco incerto, o modelo de experimentação animal reforça o paradigma da sociedade de risco, uma vez que não é possível estabelecer parâmetros de tolerabilidade ou toxidade a partir de um modelo animal. Acerca da inaplicabilidade dos resultados da experimentação animal em seres humanos, registre-se:

Tem sido demonstrado que os resultados da experimentação animal são inaplicáveis aos seres humanos. Existe uma lei natural relacionada ao metabolismo (a soma de todos os processos químicos e físicos encontrados nos organismos), de forma que uma reação que foi estabelecida para uma espécie é válida somente para aquela espécie em particular, e não para outra. Às vezes, 2 espécies bem próximas, como o rato e o camundongo, podem reagir de maneira totalmente diferente - Dr. Gianni Tamino, pesquisador da Universidade de Pádua e membro do Parlamento Italiano (apud GREIF; TRÉZ, 2000, p. 80).

Adentrar-se-á, a seguir, na base da experimentação animal, aprofundando-se dois dos modelos animais mais utilizados, atualmente.

\subsection{EXPERIMENTAÇÃO ANIMAL}

Definida como toda e qualquer prática que utiliza animais para fins científicos ou didáticos, a experimentação animal remonta a tempos imemoriais.

Sobre a datação do referido modelo de experimentação animal, vale salientar:

380 anos. Essa é a idade de um modelo que passou a ser sistematicamente explorado, se considerarmos como marco a publicação da obra Exercitatio Anatomica de Motu Cordis et Sanguinis in Animalibus (Exercício anatômico sobre o movimento do coração e sangue nos animais), do médico inglês William Harvey (1578-1657), em 1628. Essa obra é a primeira publicação resultado da observação sistemática de animais. A importância de Harvey foi tamanha que serviu de inspiração para um de seus contemporâneos: ninguém menos que René Descartes (1596-1650), importante pensador cujo mérito na formação do espírito científico já é bastante conhecido (MAGALHÃES; RALL, 2010, p. 147).

O racionalismo do francês René Descartes (1596-1650) contribuiu, em muito, para a exclusão dos animais da esfera das preocupações morais humanas. Descartes justificava a exploração dos animais ao afirmar que eles seriam somente autômatos ou máquinas destituídas de sentimentos, incapazes, portanto, de experimentar sensações de dor e de prazer. Tornaramse famosas as vivissecções de animais feitas pelos seus seguidores na Escola de Port-Royal, 
durante as quais os ganidos dos cães seccionados vivos e conscientes eram interpretados não como um sinal de dor, mas como um simples ranger de uma máquina. Foi o auge da teoria do animal-machine (TRÉZ, 2008, p. 43).

Mesmo após três séculos e meio (no decorrer dos quais as ciências da mente tiveram seu florescimento e recuaram em suas visões instrumentalizadoras), as teses de Descartes influenciam, até hoje, o mundo da ciência experimental. A teoria mecanicista da natureza animal dá sustentação à crença difundida entre os cientistas, pelo menos até há duas décadas, de que os animais são destituídos da consciência da dor, por serem destituídos da linguagem e do pensamento. A linguagem e o pensamento, para Descartes, são duas habilidades fundamentais para que um ser sensível possa ter experiência consciente da dor e, consequentemente, possa sofrer. Os experimentos dolorosos feitos em animais têm em Descartes seu patrono (FELIPE, 2007, p. 41).

O conhecimento científico ocidental encontra-se, ainda hoje, contaminado com as ideias de René Descartes expostas em 1637, em sua obra Discurso do Método. De igual forma, Morin (2000, p. 26) denomina o paradigma cartesiano de o grande paradigma do Ocidente, imposto pelo desdobramento da história europeia a partir do Século XVII.

Atualmente, no campo da experimentação, eis as principais categorias em que se insere a utilização de animais: 1) Pesquisa básica (biológica, comportamental ou psicológica) referente à testagem de hipóteses sobre questões teóricas fundamentais, tais como a natureza da duplicação do DNA e funções cerebrais; 2) Pesquisa aplicada (biomédica e psicológica) relacionada à formulação e testes de hipóteses sobre doenças, disfunções, defeitos genéticos etc. A distinção entre esta categoria e a anterior, muitas vezes, não apresenta ponto específico de corte; 3) Desenvolvimento de substâncias químicas e drogas terapêuticas, a qual difere das demais categorias eis que visa à busca de substância específica, mais do que o conhecimento propriamente dito; 4) Pesquisas voltadas ao aumento da produtividade e eficiência na prática agropecuária, incluindo ensaios alimentares, estudos de metabolismo, estudos na área de reprodução, aumento da produção leiteira etc.; 5) Testes de várias substâncias quanto a sua segurança, potencial de irritação e grau de toxidade. Dentre essas substâncias, incluem-se cosméticos, aditivos alimentares, herbicidas, pesticidas, químicos industriais e drogas (de uso veterinário ou humano); 6) Uso de animais em instituições educacionais para demonstrações, dissecção, treinamento cirúrgico, indução de distúrbios com finalidades demonstrativas, projetos científicos relacionados ao ensino; 7) Uso de animais para extração de drogas $e$ 
produtos biológicos, tais como vacinas, sangue, soro, anticorpos monoclonais, proteínas de animais geneticamente modificados para produzi-las entre outros (PAIXÃO; SCHRAMM, 2008, p. 22-23).

O foco desta pesquisa ateve-se preponderantemente à quinta categoria de experimentação animal supracitada, qual seja, aquela atinente aos testes de substâncias quanto à segurança, potencial de irritação (tolerabilidade) e de toxidade.

Regan (2006, p. 208) expõe que, testes de toxidade diferentes usam métodos diferentes. Às vezes, alguns animais são forçados a ingerir a substância testada; noutras, são forçados a inalá-la; em outros casos, a substância é aplicada na sua pele ou nos olhos.

Tocante aos testes feitos em animais, dois deles são mais comuns: o teste Draize e o teste LD50, cujos procedimentos serão a seguir descritos, a título informativo.

Quanto ao teste Draize, há mais de 30 anos a indústria de cosméticos e produtos de limpeza o utiliza em animais, para verificar o risco de infecção na pele e nos olhos de seres humanos. O teste, criado pelo cientista americano John Draize em 1944, consiste em colocar solução ou substância sólida do cosmético em teste, em forma concentrada, nos olhos ou na pele dos animais. São observadas as reações causadas nos dias seguintes ao teste. Um dos animais mais utilizados é o coelho, por ser um animal "barato, manso e ter olhos grandes". Quando as substâncias químicas são colocadas em seus olhos, eles pulam, choram, se contorcem de dor e tentam sair da jaula. Para evitar que consigam esfregar os olhos e retirar as substâncias, eles são presos em compartimentos onde não podem se mexer, exceto a cabeça, única parte do corpo visível. Às vezes, faz-se necessário o uso de clipes de metal para que as pálpebras sejam forçadas a ficar abertas permanentemente. Durante esse processo, nenhuma anestesia é usada, e os coelhos muitas vezes ficam cegos. Depois desse período de observação e sofrimento, os animais são mortos, para que sejam também estudados os efeitos internos das substâncias testadas ou porque não vela a pena mantê-los vivos (CHUAHY, 2009, p. 64-65).

Já o teste LD50 (Lethal Dose 50 ou Dose Letal de 50\%) é utilizado em animais desde os anos 1920, para medir a toxidade de substâncias encontradas em produtos como detergente, pasta de dente, conservantes de alimentos e loções para o corpo. Os ingredientes em teste são ingeridos pelos animais em alta dose através de um tubo enfiado no esôfago até o estômago. Os cientistas diminuem a dosagem progressivamente, durante certo período de tempo, até que permaneçam vivos 50\% dos animais. Quando esse número é atingido, os pesquisadores podem determinar a dosagem segura para uso humano. O teste dura vários dias, 
durante os quais os animais sofrem dores, diarreia, convulsões e sangramento nos olhos e na boca. Os que conseguem sobreviver são mortos já que não têm mais valor científico (CHUAHY, 2009, p. 65).

À guisa do que se expôs acerca do controvertido tratamento dispensado aos animais em laboratório, hoje não paira dúvida acerca da senciência animal, ou seja, a capacidade que os animais possuem de sentir dor (ou prazer). Nesse aspecto, em 7 de julho de 2012, na Universidade de Cambridge, no Reino Unido, ocorrera a Memorial Conference on Consciousness in Human and non-Human Animals, que resultou na Declaração de Cambridge sobre a Consciência em Animais Humanos e Não Humanos, assinada por grupo internacional de neurocientistas, neurofarmacologistas, neurofisiologistas, neuroanatomistas e neurocientistas computacionais cognitivos, na presença do físico Stephen Hawking.

Eis o teor do referido manifesto de Cambridge:

\begin{abstract}
A ausência de neocortex não parece impedir um organismo de experimentar estados afetivos. Evidências convergentes indicam que animais não humanos têm substratos neuroanatômicos, neuroquímicos e neurofisiológicos de consciência, juntamente com a capacidade de demonstrar comportamentos intencionais. Consequentemente, o peso das evidências mostra que humanos não são os únicos possuidores de substratos neurológicos que geram consciência. Animais não humanos, incluindo mamíferos e pássaros, e muitas outras criaturas, incluindo polvos, também possuem estes substratos neurológicos ${ }^{2}$.
\end{abstract}

Não obstante, há quem afirme que é difícil interpretar o comportamento animal para saber quando ele está sentindo dor e a intensidade desta dor. Nesse sentido, importa ver que, quanto mais afastado este animal está do homem na escala filogenética, mais difícil será também a sensibilização do ser humano para com o desconforto animal. Existem fatores objetivos que estão associados a movimentos ou vocalização que permite que se identifique a dor animal. Os animais próximos aos humanos na escala filogenética costumam apresentar resposta a dor similar a nós. É muito mais simples detectar a dor em vertebrados superiores. A pergunta é: existe interesse em que seja detectada dor em espécies consideradas inferiores quando nos procedimentos de investigação ou docência? Esse fator é eticamente relevante? (FEIJÓ, 2005, p. 69).

A seguir, procurar-se-á responder esse último questionamento, a partir da análise do princípio ético da igual consideração de interesses, proposto por Peter Singer.

\footnotetext{
2 Mais informações sobre a Conferência e a Declaração, inclusive relatos na mídia, em: <http://fcmconference.org/>. O texto da declaração pode ser lido em: $<$ http://fcmconference.org/img/CambridgeDeclarationOnConsciousness.pdf $>$.
} 


\section{PRINCÍPIO DA IGUAL CONSIDERAÇÃO DE INTERESSES}

Para se compreender a importância do princípio da igual consideração de interesses, é necessário trazer à baila o conceito de especismo.

O termo especismo designa a forma discriminatória pela qual seres humanos tratam seres de outras espécies animais como se estes existissem exclusivamente para servir aos interesses daqueles. Nesse sentido, interesses e preferências de um ser humano sempre são colocados como inquestionavelmente superiores e, portanto, prioritários em relação aos interesses de todos os demais animais, ainda que alguns interesses expressos dos animais sejam exatamente os mesmos manifestos em humanos, ou mesmo superiores aos daqueles. $\mathrm{O}$ especismo tem seu fundamento na percepção e na constatação das diferenças aparentes determinadas pelo padrão biológico dos seres em apreço. Se um determinado interesse aparece em um ser constituído biologicamente em uma espécie animal não humana, os seres humanos deixam de considerá-lo moralmente (FELIPE, 2003, p. 83).

O campo de utilização de animais em experiências talvez seja o que evidencia mais claramente o especismo. Ao lado do uso de animais para alimentação, o uso de animais enquanto objeto de pesquisas constituem exemplos de um especismo sistemático e praticado em larga escala (SINGER, 2002, p. 75-78).

Em 1973, o psicólogo britânico Richard D. Ryder (1940-) apresentou o neologismo especismo, para definir a discriminação habitual que é praticada pelos seres humanos contra as outras espécies.

Por sua vez, o filósofo utilitarista Peter Singer (1946-) tomou emprestado o conceito de especismo para desenvolver os argumentos de sua célebre obra Libertação Animal, publicada em 1975. Tal livro é considerado a pedra de toque que dera origem a um verdadeiro movimento pelos direitos dos animais, em todo o mundo.

A obra de Singer inicia ao modo de manifesto pelos direitos animais, e seu argumento é: se os animais são capazes de sentir prazer e dor, como os seres humanos, eles possuem interesses que merecem consideração.

Para Singer, a realização de experiências com animais evidencia, através de inúmeros casos concretos, que os benefícios para os seres humanos são inexistentes ou muito incertos, ao passo que as perdas para membros de outras espécies são concretas e inequívocas. Consequentemente, as experiências indicam uma falha na atribuição de igual consideração aos interesses de todos os seres, a despeito da espécie a que pertençam (SINGER, 2002, p. 77).

Revista de Biodireito e Direitos dos Animais | e-ISSN: 2525-9695| Minas Gerais | v. 1 | n. 2 | p. 103 - 121 | Jul/Dez. 2015. 
Acerca dos objetivos da pesquisa com animais, vale ressaltar o interesse das indústrias de novos cosméticos e aditivos alimentícios:

\begin{abstract}
As pessoas às vezes pensam que as experiências com animais atendem a objetivos médicos vitais e podem ser justificadas com base no fato de que aliviam mais sofrimento do que provocam. Essa confortável crença não passa de um engano. Os laboratórios testam novos xampus e cosméticos que estão pretendendo comercializar pingando soluções concentradas desses produtos nos olhos de coelhos, num teste conhecido como "teste de Draize" [...]. Os aditivos alimentícios, inclusive corantes e conservantes artificiais, são testados com o que se conhece como $\mathrm{LD}_{50}-$ um teste que tem por finalidade encontrar a "dose letal”, ou o nível de consumo que levará à morte cinquenta por cento de uma amostra de animais. Ao longo do processo, quase todos os animais ficam doentes, até que alguns finalmente morrem, e outros se restabelecem. Esses testes não são necessários para impedir o sofrimento humano: mesmo que não existisse outra alternativa ao uso de animais para testar a segurança dos produtos, já dispomos de um número suficiente de xampus e corantes para alimentos. Não há necessidade alguma de desenvolver outros, que podem mostrar-se perigosos (SINGER, 2002, p. 75-76).
\end{abstract}

A aplicação do princípio da igualdade como igual consideração de interesses significa que nenhum indivíduo tem seus direitos assegurados à custa do sacrifício de interesses ou preferências semelhantes de outros indivíduos. Todos têm seus interesses assegurados, por mais variados que sejam em relação uns aos outros, desde que não sejam satisfeitos às custas desses mesmos interesses ou até de interesses mais elevados dos demais (FELIPE, 2003, p. 94).

Se um ser sofre, não deveria haver nenhuma justificativa de ordem moral para recusar-se a levar esse sofrimento em consideração. Seja qual for a natureza do ser, o principio da igualdade exige que o sofrimento seja levado em conta em termos de igualdade com o sofrimento semelhante - até onde possamos fazer comparações aproximadas - de qualquer outro ser. Quando um ser não for capaz de sofrer, nem de sentir alegria ou felicidade, não haverá nada a ser levado em consideração. É por esse motivo que o limite de sensibilidade é o único limite defensável da preocupação com os interesses alheios. Demarcar esse limite através de uma característica, como a inteligência ou a racionalidade, equivaleria a demarcá-lo de modo arbitrário (SINGER, 2002, p. 67-68).

Albuquerque e Medeiros (2015, p. 24) ressaltam que a correta utilização dos animais não humanos, se é que é possível realizar tal assertiva, no âmbito da docência e da pesquisa científica, poderia ser assegurado pelo Direito. E esse tema é tão relevante que o próprio legislador penal a considerou na edição da Lei Ambiental, instituindo uma figura típica específica no artigo $32, \S 1^{\circ}$, da Lei n. 9.605/98, incorre nas mesmas penas quem realiza experiência dolorosa ou cruel em animal vivo, ainda que para fins didáticos ou científicos, quando existirem recursos alternativos. 
Acerca da existência de métodos e meios substitutivos ao modelo animal in vivo, na ciência médica, estudiosos resumem o que hoje estaria disponível para auxiliar cientistas e professores na transição do modelo animal para outros métodos, não agressivos, de experimentação. Os mais importantes são: a) modelos matemáticos e de computador da relação entre anatomia e fisiologia; b) uso de organismos inferiores, tais como bactérias e fungos, para testes de mutagenicidade; c) desenvolvimento de técnicas in vitro mais sofisticadas, incluindo o uso de frações subcelulares, sistemas celulares breves (suspensão celular, biópsia de tecidos, perfusão de órgãos inteiros) e cultura de tecidos (a conservação de células vivas num meio nutritivo por 24 horas ou mais); d) mais confiança em estudos humanos, incluindo epidemiologia, vigilância pós-vendas, e um uso conscienciosamente regulamentado de voluntários humanos (FELIPE, 2007, p. 118).

Vale salientar, relativamente ao uso de animais no ensino universitário, a existência de métodos alternativos, listados resumidamente por Jukes e Chiuia (apud FELIPE, 2007, p. 119): a) filmes e vídeos; b) modelos, manequins e simuladores; c) simulação por computador e multimídia; d) estudos em cadáveres e tecidos obtidos de forma ética; e) trabalho clínico com pacientes animais e voluntários; e) experimentos auto-infligidos pelos próprios estudantes; f) laboratórios in vitro; $\mathbf{g}$ ) estudo de campo.

A busca de novas tecnologias, a exemplo de simulações por computador, cálculos matemáticos, materiais sintéticos e, principalmente, tecidos vivos, sinaliza uma abertura para se pensar uma ciência mais ética e respeitosa, atenta ao princípio da igual consideração de interesses.

\section{CONCLUSÃO}

Ante os fatos trazidos, pode-se concluir que o modelo da experimentação animal, ao invés de produzir segurança, ele intensifica os riscos à vida dos seres humanos.

Como foi possível verificar, a prática da experimentação animal remonta a tempos imemoriais, e em sua gênese está a ideia de que os animais seriam autômatos ou máquinas destituídas de sentimentos, incapazes de experimentar sensações de dor ou prazer.

Contudo, atualmente não restam dúvidas de que os animais não humanos, sobretudo aqueles utilizados como instrumentos em pesquisas biomédicas, são dotados de senciência. 
Nesse sentido, a Declaração de Cambridge sobre a Consciência em Animais Humanos e Não Humanos, de 2012, vem ao encontro das pesquisas anteriormente documentadas nesse sentido.

Viu-se que, não obstante a justificativa de que os modelos animais são imprescindíveis para a cura de doenças, grande parte dos testes é realizada com fins puramente mercadológicos, como a produção de novos cosméticos, aditivos alimentares, herbicidas, pesticidas, químicos industriais e drogas (de uso veterinário ou humano).

Como se observou, a análise toxicológica das experiências com animais agrava o estado da sociedade de risco porquanto se trata de um equívoco estender os resultados de um experimento com animais para seres humanos, e porque o efeito sobre o ser humano só pode ser estudado de maneira confiável no próprio ser humano.

Nesse sentido, o princípio da igual consideração de interesses pode auxiliar como importante norteador nas pesquisas científicas, sobretudo na criação de modelos substitutivos à utilização de animais. Além de atenuar os riscos sobre os seres humanos (já que não é possível estabelecer parâmetros de tolerabilidade ou toxidade a partir de um modelo animal), ao se substituir a cultura violenta e especista presente nas pesquisas com animais, contribui-se para a construção de uma ciência mais respeitosa para os seres humanos e não humanos.

\section{REFERÊNCIAS}

ALBUQUERQUE, Letícia; MEDEIROS, Fernanda. Lei Arouca: legítima proteção ou falácia que legitima a exploração? XXIII Encontro Nacional do CONPEDI/UFSC. Florianópolis: CONPEDI, 2014, v. II, p. 307-336. Disponível em: <http://www.publicadireito.com.br/artigos/?cod=e5a419ed77a4e034>. Acesso em: 28 jul. 2015 .

ANTUNES, Celso. Uma aldeia em perigo: os grandes problemas geográficos do século 20. 1. ed. Petrópolis: Vozes, 1977, 172 p.

BECK, Ulrich. Sociedade de risco: rumo a uma outra modernidade. 2. ed. São Paulo: Editora 34, 2011, $384 \mathrm{p}$.

; GIDDENS, Anthony; LASH, Scott. Modernização reflexiva: política, tradição e estética na ordem social moderna. 1. ed. São Paulo: UNESP, 1997, 264 p.

CANOTILHO, José Joaquim Gomes. Direito Constitucional. 7. ed. Coimbra: Coimbra, 2003, 1522 p. 
CENCI, Daniel Rubens; KÄSSMAYER, Karin. O Direito ambiental na sociedade de risco e o conceito de justiça ambiental, 2009. Disponível em:

<http://www.anppas.org.br/encontro4/cd/ARQUIVOS/GT11-1015-886-

20080510203835.pdf>. Acesso em: 30 jul. 2015.

CHUAHY, Rafaella. Manifesto pelos direitos dos animais. Rio de Janeiro: Record, 2009, $252 \mathrm{p}$.

DECLARAÇÃO DE CAMBRIDGE SOBRE A CONSCIÊNCIA ANIMAL. Disponível em: $<$ http://www.labea.ufpr.br/portal/wp-content/uploads/2014/05/Declara\%C3\%A7\%C3\%A3ode-Cambridge-sobre-Consci\%C3\%AAncia-Animal.pdf>; <http://fcmconference.org/>. Acesso em: 30 ago. 2015.

EUROPA AINDA ESTÁ CONTAMINADA POR CHERNOBYL, DIZ ESTUDO. 19 de abril de $2006 . \quad$ Disponível em: <http://www.bbc.com/portuguese/reporterbbc/story/2006/04/060419_chernobylmarciars.shtm 1>. Acesso em: 14 ago 2015.

FEIJÓ, Anamaria. Utilização de animais na investigação e docência: uma reflexão ética necessária. Porto Alegre: EDIPUCRS, 2005, 145 p.

FELIPE, Sônia T.. Ética e experimentação animal: fundamentos abolicionistas. Florianópolis: Editora da UFSC, 2007, 351 p.

Por uma questão de princípios: alcance e limites da ética de Peter Singer em defesa dos animais. Florianópolis: Fundação Boiteux, 2003, 211 p.

FRADE, Catarina. O direito face ao risco. Revista Crítica de Ciências Sociais, setembro de 2009. Portugal. Disponível em: <www.ces.uc.pt/rccs/includes/download.php?id=2035>. Acesso em: 27 jul. 2015.

FREITAS, Vladimir Passos de (Org.). Direito ambiental em evolução. 1. ed. Curitiba: Juruá, 2005, 364 p. 4 v.

GARCIA, Rogério Maia. A sociedade do risco e a (in)eficácia do direito penal na era da globalização. LEX Editora S.A. São Paulo. Disponível em: <http://sisnet.aduaneiras.com.br/lex/doutrinas/arquivos/RISCO.pdf>. Acesso em 29 jul. 2015.

GREENPEACE BRASIL. Novo estudo do Greenpeace revela que número de mortes por câncer de Chernobyl pode chegar a 93 mil. 17 de abril de 2006. Disponível em:

$<$ http://www.greenpeace.org/brasil/pt/Greenblog/vtimas-de-chernobyl/blog/33819/>. Acesso em 28 jul. 2015.

GREIF, Sérgio; TRÉZ, Thales. A verdadeira face da experimentação animal. Rio de Janeiro: Sociedade Educacional "Fala Bicho", 2000, 200 p. 
GUATTARI, Félix. As três ecologias. 14. ed. São Paulo: Papirus, 2003, 56 p. LEFF, Enrique. Epistemologia ambiental. 4. ed. São Paulo: Cortez, 2006, 240 p. MADERS, Angelita Maria. O Direito frente à incerteza: um olhar sobre os avanços biotecnológicos à luz do Biodireito e da teoria da complexidade de Edgar Morin. Prisma Jurídico, janeiro-junho de 2010. Disponível em: <http://www.redalyc.org/articulo.oa?id=93416940006>. Acesso em: 8 mar. 2015.

MAGALHÃES, Valéria Barbosa; RALL, Vânia (Orgs.). Reflexões sobre a tolerância: direitos dos animais. São Paulo: Humanitas; Evolução, 2010, 232 p.

MARCHESAN, Ana Maria Moreira; STEIGLEDER, Annelise Monteiro; CAPPELLI, Sílvia. Direito ambiental. 2. ed. Porto Alegre: Verbo Jurídico, 2005, 216 p.

MORATO LEITE, José Rubens (Coord). Manual de Direito Ambiental. São Paulo: Saraiva, 2015, 776 p.

; AYALA, Patryck de Araújo. Direito ambiental na sociedade de risco. 2. ed. Rio de Janeiro: Forense Universitária, 2004, 368 p.

MORIN, Edgar. Os sete saberes necessários à educação do futuro. 11. ed. São Paulo: UNESCO/Cortez, 2006, 118 p.

PAIXÃO, Rita Leal; SCHRAMM, Fermin Roland. Experimentação animal: razões e emoções para uma ética. Niterói: EdUFF, 2008, 206 p.

REGAN, Tom. Jaulas vazias: encarando o desafio dos direitos animais. Porto Alegre: Lugano. 2006, 266 p.

REVISTA ÉPOCA. 25 anos do desastre de Chernobyl. 26 de abril de 2011. Disponível em: $<$ http://revistaepoca.globo.com/Revista/Epoca/0,,EMI228567-15227,00.html >. Acesso em 2 ago. 2015.

SINGER, Peter. Ética Prática. 3. ed. São Paulo: Martins Fontes, 2002, 399 p.

Libertação animal: o clássico definitivo sobre o movimento pelos direitos dos animais. São Paulo: WMF Martins Fontes. 2010, 461 p.

TRÉS, Thales (Org.). Instrumento animal: o uso prejudicial de animais no ensino superior. Bauru: Canal 6, 2008, 214 p. 